\title{
Wide World of Beverage Research: Reviews of Current Topics
}

\author{
Alessandra Del Caro
}

check for

updates

Citation: Del Caro, A. Wide World of Beverage Research: Reviews of

Current Topics. Beverages 2021, 7, 17.

https: / / doi.org/10.3390/

beverages7020017

Received: 22 December 2020

Accepted: 25 January 2021

Published: 1 April 2021

Publisher's Note: MDPI stays neutral with regard to jurisdictional claims in published maps and institutional affiliations.

Copyright: (C) 2021 by the author. Licensee MDPI, Basel, Switzerland. This article is an open access article distributed under the terms and conditions of the Creative Commons Attribution (CC BY) license (https:// creativecommons.org/licenses/by/ $4.0 /)$
Dipartimento di Agraria, Università degli Studi di Sassari, Viale Italia 39/A, 07100 Sassari, Italy; delcaro@uniss.it

In 2015, the journal Beverages (ISSN 2306-5710) was launched to provide insight into the beverage industry. After five years, to celebrate this anniversary, we are delighted to present a Special Issue on the topic of "Wide World of Beverage Research: Reviews of Current Topics". This Special Issue gathers seventeen articles that cover a wide range of beverages such as wine, beer, functional beverages, fruit juices, alcohol-free beverages, fermented functional beverages, fortified wines, and beverages containing probiotics, prebiotics, and symbiotics.

The increasing demand for and interest in alcoholic beverages has been explored [1] by Young and Lee who have provided information to researchers and industries on factors influencing consumer wine perception after reviewing sensory studies on wine published over the past 10 years. This review put in evidence the need to perform studies that achieve new insights into consumers and to deeply explore the relationship between wine quality and actual consumer perception. Another interesting review [2] explored the role of the socalled "cork taint" due to the presence of musty and moldy taint. The author analyzed the role of different molecules responsible for this defect and also added information about the possible prevention or remedial treatments to cork taint. Once again, the author considered it desirable to conduct new studies focused on the prevention of this important wine defect. In terms of food safety, Schmid and Welle [3] analyzed beverage packaging such as PET bottles, glass bottles, metal cans, and cardboard multilayers to assess a potential migration of some compounds from the different materials reported, especially considering European food law with its specific migration limits and testing conditions. They conclude that the current literature review of chemical migration from beverage packaging materials did not reveal any critical compounds. The migration tests carried out during shelf life did not show values above the specific migration limits.

Wine traceability and authenticity needs tools to be able to give to consumers this important information. In the review [4], the authors explored the role of a simple, fast and cost-effective way, FT-IR spectroscopy, to analyze different components without the need for chemicals or preparatory steps. This successful technique could be tested and potentially implemented, as suggested by the authors, by constructing a larger database with wines of different geographic region and produced with different varieties and technological processes.

Kessler et al. [5] examined the role of automated facial expression analysis (AFEA) on beverages. Despite the huge diversity in the literature about the methods used in the AFEA, these authors evidenced clear benefits to using AFEA in product and package development, leading to a more comprehensive understanding of the consumer.

Mellor et al. [6] focused their review on the potential health benefits of low-alcohol and alcohol-free beer. Hops, polyphenols and phenolics, and prebiotics and probiotics were explored as well as the effects of brewing and maturation processes. The aim of the review was to evidence the potential healthy role of beer without alcohol or with a low alcohol content. The review underlined the importance of innovation in increasing beer palatability, maximizing healthy effects, and minimizing the potentially harmful effects of alcohol consumption.

Functional beverages are an emerging topic of the last years. In this context, Cong et al. [7], with their review, have provided information about legislation to the scientific 
community on differences among different countries of the Asia Pacific region. Moreover, they suggest promoting new research on consumer-oriented studies on functional beverages. Within the same topic, another review [8] explored the world of probiotics and their survival and performance in beverages. Again, the effect of different technological stresses on their resistance was reported. Another important topic in wine is protein instability. Cosme et al. [9] gave an overview on the different aspects involved in wine protein instability and reviewed the technological alternatives useful to stabilize wines with problems of protein instability. This topic was further explored by the analysis of the advantages and disadvantages of protein stability tests and by strategies used to control this instability. An overview of the recent developments of membrane operation with the aim to clarify or concentrate and recuperate aroma compounds in fruit juice processing was explored by Conidi et al. [10]. They highlighted the optimal role of microfiltration and ultrafiltration operations on the fining step of the juice processing, especially in terms of low energy requirements, the reduction of thermal damage and waste products, and finally, the ease of cleaning and maintenance. The chemical and toxicological effect of the biogenic amines present in alcohol-free beverages was also summarized [11]. Its importance is due to the increasing consumption in recent years of alcohol-free beverages. This fact implies an ongoing monitoring of drink quality both to protect human health and to monitor all of the production chain. Kim and Adhikari [12] provided to the scientific community an overview of the market for "Kombucha", which is a recently popular fermented functional beverage produced by symbiotic bacteria and yeasts. This review pointed out its importance as a low-calorie- and low-sugar-content beverage, although the authors underlined the scarce literature present on the sensory and consumer perception for this product. They invited the scientific community to promote new research in this field. An important review was made by Perestrelo et al. [13] on Madeira wine, a fortified wine with an important impact on the Madeira island economy. The volatile and non-volatile profile was depicted very deeply by analyzing more than 150 different papers that make it possible to gain a complete overview on this type of wine. The possibility to produce beverages to promote endurance performance by supplementing them with arginine and citrulline, with potential additional physiological benefits, was explored by Speer et al. [14]. In this review, the authors reported the range of arginine and citrulline concentrations used, assessed the effects of both amino acids (individually or in combination) relating to performance outcomes, and considered the possibility to provide these supplements in the form of a beverage. They concluded that further research is needed, especially to modulate the release of these amino acids pre-, during, and post-endurance performance. The literature on traditional fruit and vegetable fermented beverages and new trends, the diversity of lactic acid bacteria $(\mathrm{LAB})$, and how the processing steps can affect the LAB was examined [15]. The main findings were that LAB-fermented fruit and vegetable beverages may provide benefits for metabolic disease management, and the encapsulation or addition of antioxidants have a crucial role in maintaining probiotic LAB viability. The last review [16] of this Special Issue summarized the pros and cons of different approaches, reported in the literature, to design new yeast for craft brewing. The authors stressed the important role of new strategies such as the use of non-conventional yeasts or of $\mathrm{S}$. cerevisiae natural variants from alternative bioreservoirs that can significantly enrich the beer aroma profile. Again, they found that the novel discoveries on the genomic signatures of brewing relevant phenotypes can enhance innovation in beer starter culture selection. This Special Issue ends with a perspective [17] on the therapeutic performance and properties of dairy and non-dairy beverages in terms of probiotic, prebiotic, and symbiotic activities. This exhaustive perspective put in evidence that the effects of probiotics in many diseases have not yet been fully investigated, and their mechanisms of action for promoting health and controlling disorders needs further investigation.

Funding: This research received no external funding.

Institutional Review Board Statement: Not applicable. 
Informed Consent Statement: Not applicable.

Acknowledgments: The editors of this Special Issue would like to acknowledge all the authors and reviewers who have kindly shared their experience, knowledge, time, and effort. We would also like to express our gratitude to MDPI Beverages, in particular to Tina Tian for the opportunity to be guest editors of this Special Issue.

Conflicts of Interest: The authors declare no conflict of interest.

\section{References}

1. Yang, J.; Lee, J. Current Research Related to Wine Sensory Perception Since 2010. Beverages 2020, 6, 47. [CrossRef]

2. Cravero, M.C. Musty and Moldy Taint in Wines: A Review. Beverages 2020, 6, 41. [CrossRef]

3. Schmid, P.; Welle, F. Chemical Migration from Beverage Packaging Materials-A Review. Beverages 2020, 6, 37. [CrossRef]

4. Basalekou, M.; Pappas, C.; Tarantilis, P.A.; Kallithraka, S. Wine Authenticity and Traceability with the Use of FT-IR. Beverages 2020, 6, 30. [CrossRef]

5. Kessler, S.J.; Jiang, F.; Hurley, R.A. The State of Automated Facial Expression Analysis (AFEA) in Evaluating Consumer Packaged Beverages. Beverages 2020, 6, 27. [CrossRef]

6. Mellor, D.D.; Hanna-Khalil, B.; Carson, R. A Review of the Potential Health Benefits of Low Alcohol and Alcohol-Free Beer: Effects of Ingredients and Craft Brewing Processes on Potentially Bioactive Metabolites. Beverages 2020, 6, 25. [CrossRef]

7. Cong, L.; Bremer, P.; Mirosa, M. Functional Beverages in Selected Countries of Asia Pacific Region: A Review. Beverages 2020, 6, 21. [CrossRef]

8. Speranza, B.; Campaniello, D.; Petruzzi, L.; Altieri, C.; Sinigaglia, M.; Bevilacqua, A.; Corbo, M.R. The Inoculation of Probiotics In Vivo Is a Challenge: Strategies to Improve Their Survival, to Avoid Unpleasant Changes, or to Enhance Their Performances in Beverages. Beverages 2020, 6, 20. [CrossRef]

9. Cosme, F.; Fernandes, C.; Ribeiro, T.; Filipe-Ribeiro, L.; Nunes, F.M. White Wine Protein Instability: Mechanism, Quality Control and Technological Alternatives for Wine Stabilisation-An Overview. Beverages 2020, 6, 19. [CrossRef]

10. Conidi, C.; Castro-Muñoz, R.; Cassano, A. Membrane-Based Operations in the Fruit Juice Processing Industry: A Review. Beverages 2020, 6, 18. [CrossRef]

11. Vinci, G.; Maddaloni, L. Biogenic Amines in Alcohol-Free Beverages. Beverages 2020, 6, 17. [CrossRef]

12. Kim, J.; Adhikari, K. Current Trends in Kombucha: Marketing Perspectives and the Need for Improved Sensory Research. Beverages 2020, 6, 15. [CrossRef]

13. Perestrelo, R.; Silva, C.; Gonçalves, C.; Castillo, M.; Câmara, J.S. An Approach of the Madeira Wine Chemistry. Beverages 2020, 6, 12. [CrossRef]

14. Speer, H.; D'Cunha, N.M.; Davies, M.J.; McKune, A.J.; Naumovski, N. The Physiological Effects of Amino Acids Arginine and Citrulline: Is There a Basis for Development of a Beverage to Promote Endurance Performance? A Narrative Review of Orally Administered Supplements. Beverages 2020, 6, 11. [CrossRef]

15. Garcia, C.; Guerin, M.; Souidi, K.; Remize, F. Lactic Fermented Fruit or Vegetable Juices: Past, Present and Future. Beverages 2020, 6, 8. [CrossRef]

16. Iattici, F.; Catallo, M.; Solieri, L. Designing New Yeasts for Craft Brewing: When Natural Biodiversity Meets Biotechnology. Beverages 2020, 6, 3. [CrossRef]

17. Nazhand, A.; Souto, E.B.; Lucarini, M.; Souto, S.B.; Durazzo, A.; Santini, A. Ready to Use Therapeutical Beverages: Focus on Functional Beverages Containing Probiotics, Prebiotics and Synbiotics. Beverages 2020, 6, 26. [CrossRef] 